\title{
Fracture Incidence, Quality of Life, and Back Pain during 18-Months Treatment with Teriparatide in Greek Postmenopausal Women with Osteoporosis: Results from the European Forsteo Observational Study
}

\author{
K. Aloumanis, ${ }^{1}$ D. Karras, ${ }^{2}$ V. Drossinos, ${ }^{1}$ E. Korelis, ${ }^{1}$ and A. Polydorakis ${ }^{1}$ \\ ${ }^{1}$ Department of Medical Research, Pharmaserve-Lilly, Kifissia, 14564 Athens, Greece \\ ${ }^{2}$ Rheumatology Department, Veterans Administration Hospital, 11521 Athens, Greece \\ Correspondence should be addressed to K. Aloumanis, aloumanis_kyriakos@lilly.com
}

Received 27 January 2011; Revised 20 April 2011; Accepted 19 July 2011

Academic Editor: Stuarts L. Silverman

Copyright $\odot 2011 \mathrm{~K}$. Aloumanis et al. This is an open access article distributed under the Creative Commons Attribution License, which permits unrestricted use, distribution, and reproduction in any medium, provided the original work is properly cited.

\begin{abstract}
Objective. To evaluate fracture incidence, effects on health-related quality of life(QoL), back pain (BP) occurrence and treatment compliance in Greek post-menopausal osteoporotic women treated with teriparatide (TPTD) for up to 18 months, in a naturalistic setting. Methods. 301 patients provided baseline information on demographic characteristics, fracture history, osteoporosis-related medication and risk factors. During treatment, QoL and BP severity were evaluated. Results. Mean (SD) age was 69.5 ( \pm 8.5$)$ years. Fracture history was reported by $92.5 \%$ of patients. Incidence of fractures (per 10,000 patients/years) ranged from 402 during 0-6 months of treatment, to 346 during 12-18 months. All 5 dimensions of QoL showed improvement. At baseline and 18 months, BP was reported by $93.2 \%$ and $64.2 \%$ of patients, respectively. BP and limitation of activities were quantified as moderate or severe by $89.9 \%$ and $62.3 \%$ of patients at baseline versus $32.4 \%$ and $14.8 \%$ at 18 months. Patients on treatment at $6,12,17$, and 18 months were $92.6 \%, 88.3 \%, 79.6 \%$, and $36.5 \%$, respectively. Conclusions. In the Greek EFOS study cohort, patients prescribed TPTD were severely osteoporotic, with considerable health-related problems. Significant improvements in QoL and BP together with low fracture rates and high compliance have been recorded during treatment.
\end{abstract}

\section{Introduction}

Fractures, whether vertebral or nonvertebral, symptomatic or radiographically identified, is the most important complication of postmenopausal osteoporosis. They are etiologically associated with increased mortality and morbidity, chronic back pain, and a deterioration of health-related quality of life (HRQoL) in women with osteoporosis [1-5]. These fractures present a social-economic burden since approximately 9 million osteoporotic fractures per year occur globally, most of which are observed in postmenopausal women [6]. The cost for their treatment in Europe alone is estimated to exceed 76 billion Euros by 2050 [7].

Today, aminobisphosphonates are the most commonly prescribed medications for the treatment of osteoporosis. By suppressing bone resorption (antiresorptive medications), they reduce the risk of new osteoporotic vertebral fractures, while some, like alendronate, have shown significant reduction of nonvertebral fractures as well [8]. Recently, anabolic antiosteoporotic agents were introduced, which, by enhancing the bone formation, increase bone mass, improve bone microarchitecture, enhance bone tolerance, and reduce osteoporotic fractures $[9,10]$. Teriparatide (TPTD), an anabolic agent, is the recombinant (1-34) N-terminal of human parathyroid hormone $\left(\mathrm{PTH}_{1-34}\right)$. In a double-blind, placebo-controlled clinical study, a 19-month TPTD treatment reduced vertebral and nonvertebral fractures in women with severe osteoporosis [10]. Furthermore, it has been identified that TPTD treatment increases bone mineral density (BMD) and reduces the risk of new osteoporotic fractures to a greater extent than that observed with alendronate 
in patients (men or women) with glucocorticoid-induced osteoporosis [11].

Ultimately, double-blind, randomized studies are the cornerstone for the confirmation of the effectiveness of any medication. However, their design and strict patient inclusion and exclusion criteria limit their potential to provide answers to questions concerning the "typical" patient in reallife clinical practice. In a recent study, it was estimated that from 120 patients with osteoporosis, $80 \%$ would not be enrolled in a double-blind, randomized study, due to comorbidity or/and their osteoporotic or other concomitant medication history [12]. Observational studies bridge that gap and complement double-blind studies, providing answers to a wide variety of clinical questions that emerge in everyday clinical practice.

In the European Forsteo Observational Study (EFOS), in contrast to clinical trials, all patients initiating TPTD in a naturalistic setting were enrolled in a 3-year prospective, noninterventional, multicenter design [13]. The results of 18 months of treatment with TPTD in the total cohort enrolled in the study have been reported [14]. The present analysis focuses on the subset of patients enrolled in Greece.

301 postmenopausal women with established osteoporosis from 31 investigative sites in Greece enrolled in the study with a total study period of 36 months (18-month TPTD treatment period and 18-month period of followup). Women enrolled in the EFOS study suffered from severe osteoporosis accompanied by serious problems in mobility and usual activities and experienced intense back pain, anxiety, depression, and diminished health-related quality of life [15]. The current analysis focuses on the results of 18-month TPTD treatment in terms of incidence of new osteoporotic fractures, back pain, health-related quality of life and compliance to treatment.

\section{Material and Methods}

The study design, patient demographics and the diseaserelated data at baseline have been published elsewhere $[13,15]$. EFOS, as a noninterventional study, included all postmenopausal women initiating TPTD in normal clinical practice. The study only excluded patients who were treated with any investigational drug or procedure at study entry, or presented with one of the known contraindications for the use of TPTD, as indicated in the compound's SPC. Patients signed an informed consent form to permit medical data to be collected. Each patient could withdraw her consent for participation in the study and leave the study without consequence. The study was conducted according to Good Clinical Practice, and Ethical Review Board permission was given for all participating investigational sites.

At baseline, patient demographics, osteoporosis and falls-related risk factors, antiosteoporotic medication(s) already received, and the current disease state were recorded. Following the initial visit, four prospective visits were conducted at 3, 6, 12, and 18 months of TPTD treatment. During these visits, patient compliance with treatment was determined from the number of TPTD doses the patient recalled missing in the month preceding the visit. New clinical vertebral and nonvertebral fractures were diagnosed and verified by an X-ray and/or by taking into account the history of orthopedic intervention. A suspected new or an exacerbation of an older fracture was determined from the clinical symptoms and findings, such as acute back pain (lumbago) and were confirmed with a new comparative Xray.

A specific questionnaire on back pain evaluation was completed at each patient's visit, incorporating information on frequency, severity of back pain, limitation of activities, and days spent in the bed due to back pain in the previous month. The patient's perceived severity of back pain was captured using a $100 \mathrm{~mm}$ visual analogue scale (VAS), with 0 representing the absence of pain and 100 the worst possible pain [16].

HRQoL was evaluated using the EQ-5D questionnaire [17], which consists of 5 parameters (mobility, self-care, usual activities, pain/discomfort, and anxiety/depression). Each of the above QoL dimensions had three levels (no problem-some problems-extreme problems). Moreover, patients expressed their perception of their QoL using a scaled VAS (ranging from 0, the worst possible QoL, to 100, the best possible QoL-EQ-5D VAS). Spontaneously reported adverse events were collected throughout the study.

\section{Statistical Analysis}

Descriptive statistics, such as frequencies, percentages, means, standard deviations (SD), and ranges, were used to describe the study population over time.

The number of fractures occurring in patients was summarized in 6-month intervals $(0-<6$ months, and $>6-12$ months, >12-18 months). The regression models used to analyze fracture rating for the total cohort are described elsewhere [14]. In the Greek subpopulation, such an analysis is not appropriate because of the small sample and thus is not presented.

Back pain and QoL results were also analyzed over this treatment period. The number and percentage of patients with improvement, no change, or worsening in each domain of the EQ-5D questionnaire were summarized at each visit and the sign test was used to determine whether significantly more patients showed improvement than worsening. Back pain changes from baseline in the VAS were analyzed using a mixed model for repeated measures, adjusting for multiple factors, as has been already reported [14]. EQ-5D HSV had a continuous, nonparametric, bimodal distribution; therefore, the Wilcoxon sign-rank test was used to assess changes from baseline in this parameter.

The number of patients reporting a change in the severity and frequency of pain, the limitation of activities, and the number of days in bed between baseline and a subsequent visit, all recorded as improvement, worsening, or no change, was also analyzed using the sign test. For the reference of "days in bed," there was no change if the difference reported was $\leq 2$ days. 
TABLE 1: Osteoporosis medications (other than teriparatide) prior and during the course of the study.

\begin{tabular}{|c|c|c|c|c|c|c|}
\hline Medication & $\begin{array}{l}\text { Past use at baseline } \\
\qquad(N=301)\end{array}$ & $\begin{array}{l}\text { Ongoing at baseline } \\
\quad(N=301)\end{array}$ & $\begin{array}{c}3 \text { months } \\
(N=297)^{\mathrm{a}}\end{array}$ & $\begin{array}{l}6 \text { months } \\
(N=282)^{\mathrm{a}}\end{array}$ & $\begin{array}{l}12 \text { months } \\
(N=280)^{\mathrm{a}}\end{array}$ & $\begin{array}{l}18 \text { months } \\
(N=278)^{\mathrm{a}}\end{array}$ \\
\hline Any medication & $83.7 \%$ & $74.0 \%$ & $78.6 \%$ & $79.0 \%$ & $81.4 \%$ & $76.9 \%$ \\
\hline Any antiresorptives & $81.7 \%$ & $34.4 \%$ & $6.8 \%$ & $7.1 \%$ & $7.9 \%$ & $9.4 \%$ \\
\hline Any bisphosphonates & $38.0 \%$ & $12.0 \%$ & $0.7 \%$ & $0.7 \%$ & $1.8 \%$ & $2.5 \%$ \\
\hline Estrogen/progestin therapy & $1.3 \%$ & $0.0 \%$ & $0.0 \%$ & $0.0 \%$ & $0.0 \%$ & $0.0 \%$ \\
\hline Estrogen therapy & $1.0 \%$ & $0.0 \%$ & $0.0 \%$ & $0.0 \%$ & $0.0 \%$ & $0.0 \%$ \\
\hline Raloxifene & $7.0 \%$ & $1.0 \%$ & $1.0 \%$ & $0.7 \%$ & $0.4 \%$ & $0.4 \%$ \\
\hline Calcitonin & $65.0 \%$ & $21.4 \%$ & $6.1 \%$ & $6.0 \%$ & $5.7 \%$ & $6.5 \%$ \\
\hline Calcium & $68.0 \%$ & $67.7 \%$ & $75.6 \%$ & $78.6 \%$ & $81.1 \%$ & $75.5 \%$ \\
\hline Vitamin D & $53.7 \%$ & $62.5 \%$ & $72.2 \%$ & $74.0 \%$ & $75.0 \%$ & $70.8 \%$ \\
\hline None reported & $16.3 \%$ & $26.0 \%$ & $21.4 \%$ & $21.0 \%$ & $18.6 \%$ & $23.1 \%$ \\
\hline
\end{tabular}

${ }^{a}$ Started since previous observation.

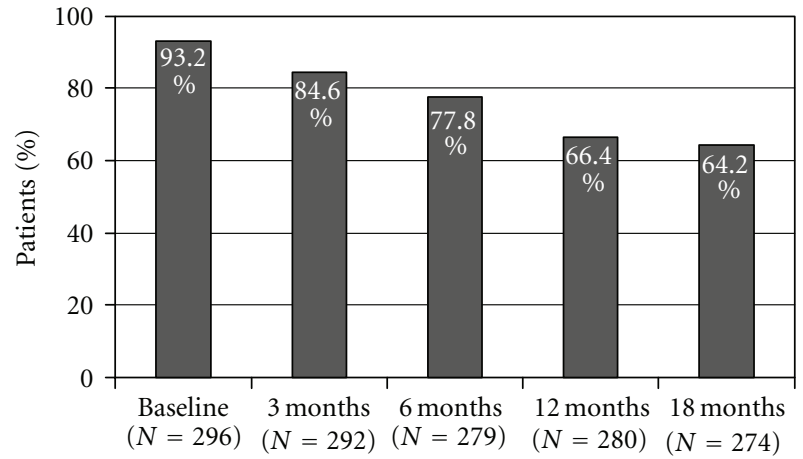

FIGURE 1: Back pain experienced.

\section{Results}

1648 patients were enrolled in the pan-European study including 301 postmenopausal women from Greece. For the Greek sample, mean age was $69.5 \pm 8.5$ years and mean BMI was $26.3 \pm 4.0$. Baseline characteristics of the total cohort and the Greek subpopulation of the EFOS study are presented elsewhere $[13,15]$. History of fracture after 40 years of age was reported by $92.5 \%$ of patients, with vertebral fracture being the most prevalent $(89.7 \%)$, while $39.5 \%$ of women had 2 or more fractures.

The majority of women $(83.7 \%)$ received prior antiosteoporotic medication(s); the most common were calcitonin $(65.0 \%)$ and bisphosphonates $(38.0 \%)$, most of which were stopped during TPTD treatment. The use of calcium and vitamin $\mathrm{D}$ was very frequent throughout the study $(75.5 \%$ and $70.8 \%$ at treatment conclusion, resp.) (Table 1).

4.1. Treatment Compliance and Safety. At 3, 6, 12, and 17 months, $94.7 \%, 92.6 \%, 88.3 \%$, and $79.6 \%$ of patients, respectively, were still receiving TPTD treatment. Interestingly persistence with treatment fell to $36.5 \%$ in the last month of treatment (as, at the time of the study, TPTD was approved for an 18-month period).
Of those patients discontinuing treatment, only $5(1.8 \%)$ reported an adverse event and $2(0.7 \%)$ died, while noncompliance and patient decision accounted for 28 (10.1\%) and physcian decision for 7 (2.5\%) discontinuations. Mean TPTD treatment duration was $504 \pm 158$ days. After 18 months, 89 of 199 patients $(44.7 \%)$ who were followed up reported some physical activity, compared with 79/291(27.1\%) who were reported to exercise at baseline.

A detailed adverse event report was not available for the Greek cohort; however, the rate of discontinuation due to adverse events is low. Safety results for the total EFOS group are presented elsewhere [14].

4.2. Incidence of New Osteoporotic Fractures. The incidence of new osteoporotic fractures during the first 6-month treatment period was 402 fractures per 10,000 patient/ years, while there were 342 and 346 fractures per 10,000 patient/ years, respectively, in the subsequent 6-month treatment periods.

BMD was not evaluated as part of this study. Where collected, BMD T-score in 18 months of treatment compared with baseline was in the lumbar spine $-2.54 \pm 0.74(N=$ $120)$ versus $-3.46 \pm 0.67(N=175)$ and the femoral neck $-2.40 \pm 0.75(N=11)$ versus $-3.07 \pm 0.58(N=35)$. As BMD was not a study endpoint, no statistical analysis is provided.

4.3. Back Pain. When asked about back pain at baseline (before TPTD initiation), 93.2\% of women reported having experienced back pain, while $39.9 \%$ reported back pain every day or almost every day. The majority of patients $(89.9 \%)$ quantified back pain as moderate or severe. Moderate or severe limitation of activities was reported by $62.3 \%$ of women. The mean (SD) VAS value for patients' perceived back pain was $59.3 \pm 27.5 \mathrm{~mm}$.

Back pain reported by patients during the previous month at each visit was reduced to $77.8 \%$ and $64.2 \%$ of patients, at 6 and 18 months of TPTD treatment, respectively (Table 2 and Figure 1). Back pain every day or almost every day was reported by $3.9 \%$ and $2.2 \%$ at the same time 
TABLE 2: Back pain reporting and qualification in the study course.

\begin{tabular}{|c|c|c|c|c|c|}
\hline$\%$ of Patients & Baseline $^{\mathrm{b}}$ & 3 months $^{\mathrm{c}}$ & 6 months $^{\mathrm{c}}$ & 12 months $^{\mathrm{c}}$ & 18 months $^{\mathrm{c}}$ \\
\hline Reporting back pain (BP) & $93.2 \%$ & $84.6 \%$ & $77.8 \%$ & $66.4 \%$ & $64.2 \%$ \\
\hline BP every/almost every day & $39.9 \%$ & $7.5 \%$ & $3.9 \%$ & $2.5 \%$ & $2.2 \%$ \\
\hline Moderate or severe BP & $89.9 \%$ & $69.4 \%$ & $50.7 \%$ & $42.4 \%$ & $32.4 \%$ \\
\hline $\begin{array}{l}\text { Moderate or severe } \\
\text { limitation of activities }\end{array}$ & $62.3 \%$ & $36.7 \%$ & $24.0 \%$ & $18.3 \%$ & $14.8 \%$ \\
\hline
\end{tabular}

${ }^{\mathrm{b}}$ During the last 12 months.

${ }^{\mathrm{c}}$ During the last month.

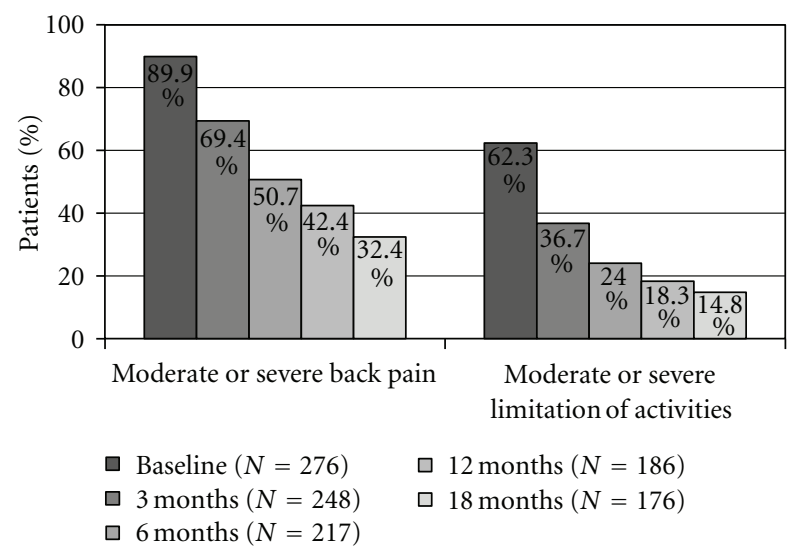

FIGURE 2: Percentage of patients with moderate or severe back pain/ limitation of activities.

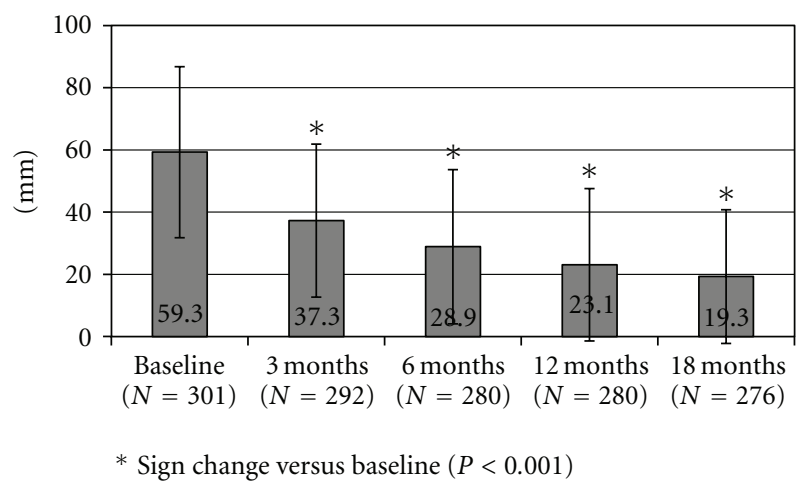

FIGURE 3: Back pain as defined by patients through the visual analogue scale tool (mm) (mean, SD).

intervals, respectively. Moderate or severe back pain was reported by $32.4 \%$ of women, while moderate or severe limitation of activities was reported by $14.8 \%$ of patients at the conclusion of the 18-month TPTD treatment period (Table 2 and Figure 2). At that time, mean VAS value for back pain was $19.3 \pm 21.5$ (Figure 3 ).

There was a statistically significant reduction in the frequency of back pain relative to that experienced prior to treatment, as well as a significant improvement in the severity of back pain (moderate or severe back pain) and the limitation of patients' activities at the end of the first, second, and third semester (i.e., 6, 12, and 18 months) of TPTD treatment $(P<0.001)$ (Table 3$)$.

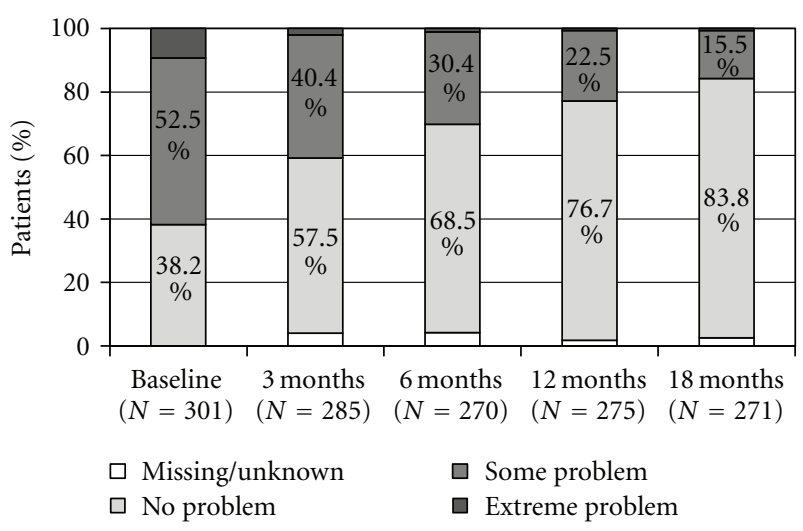

FIgure 4: EQ-5D: mobility.

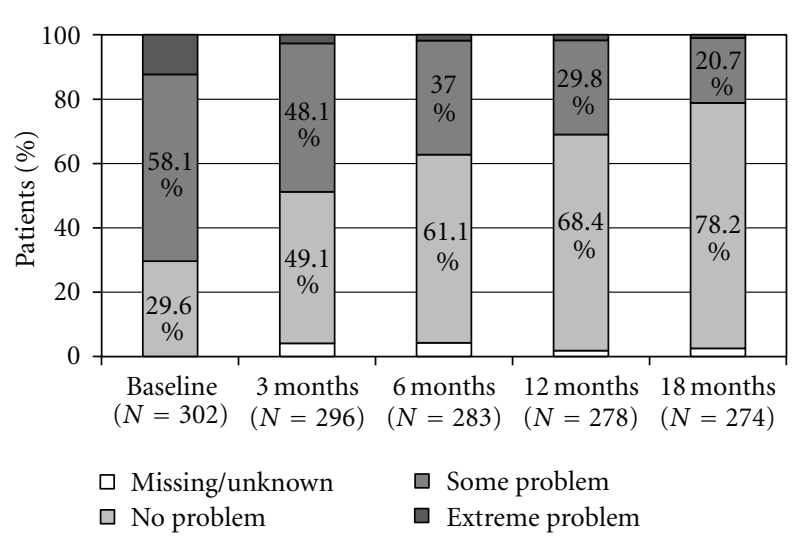

FIgUre 5: EQ-5D: usual activities.

4.4. Health-Related Quality of Life (HRQoL). Improvement was identified in all dimensions (mobility, self-care, usual activities, and pain/discomfort) of the EQ-5D questionnaire (Figures 4, 5, and 6). The mean (SD) value of the $100 \mathrm{~mm}$ VAS was $54 \pm 25$ prior to treatment initiation and $80 \pm 19$ at the conclusion of the 18-month TPTD treatment period $(P<0.001)$ (Figure 7). Median (Q1-Q3) EQ-5D HSV improved from $0.516(-0.016-0.725)$ at baseline to 0.848 $(0.725-1.000)$ at 18 months (Wilcoxon rank test: $P<0.001)$ ).

Patients also evaluated their disposition at the end of the treatment period: $45.8 \%$ reported an improvement in anxiety/depression compared with baseline $(P<0.001)$. 


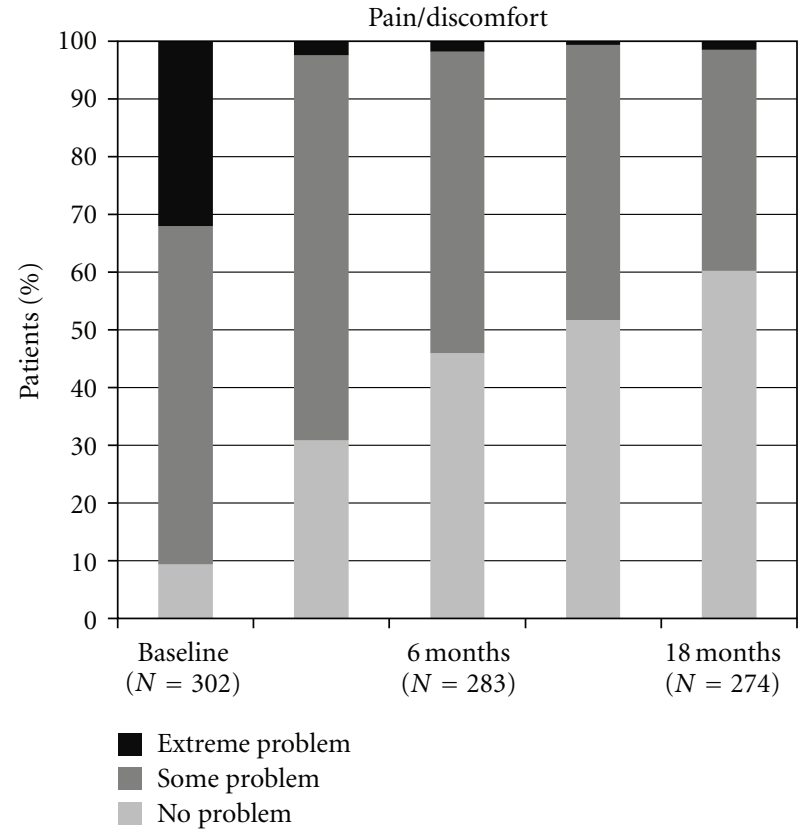

(a)

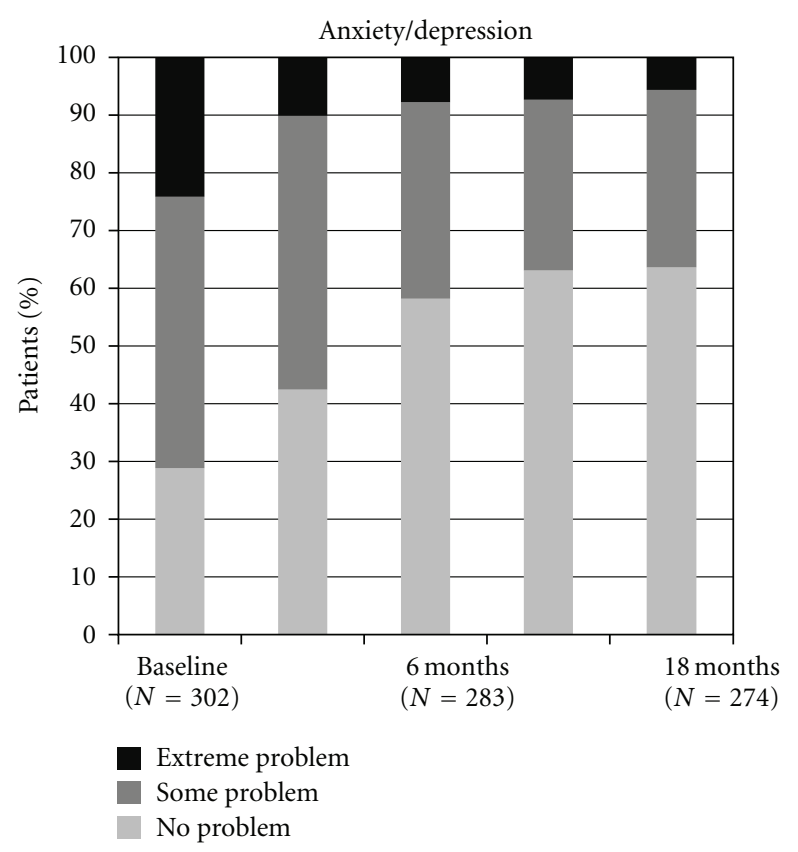

(b)

FIGURE 6: EQ-5D: pain/discomfort and anxiety/depression.

TABLE 3: \% of patients experiencing improvements in frequency and severity of back pain and limitation of activities.

\begin{tabular}{|c|c|c|c|c|}
\hline Improvement (\% of patients) & 3 months & 6 months & 12 months & 18 months \\
\hline Frequency of back pain & $69.8 \% *$ & $77.3 \% *$ & $79.9 \% *$ & $76.9 \% *$ \\
\hline Severity of back pain & $54.3 \% *$ & $65.4 \% *$ & $69.8 \% *$ & $71.6 \% *$ \\
\hline Limitation of activities & $53.1 \% *$ & $66.4 \% *$ & $68.7 \% *$ & $65.1 \% *$ \\
\hline
\end{tabular}

* Sign test, change from baseline, $P<0.001$.

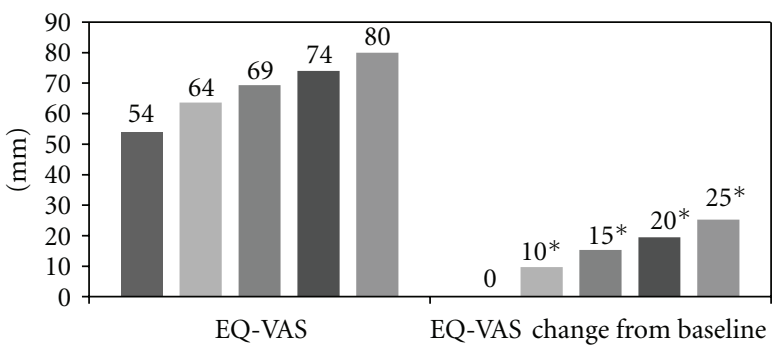

* Unadjusted sign change versus baseline $(P<0.001)$
$\begin{aligned} & \text { Baseline }(N=301) \\ & 3 \text { months }(N=295)\end{aligned} 12$ months $(N=279)$
$\square$ months $(N=282)$

FIGURE 7: EQ-5D as defined by patients through the visual analog scale tool $(\mathrm{mm})$ and EQ-5D VAS change from baseline $(\mathrm{mm})$.

\section{Discussion}

EFOS, a 3-year prospective, noninterventional, multicenter study evaluated the real-time use of TPTD as an antiosteoporotic treatment in postmenopausal women. In the overall population of 1648 osteoporotic women in EFOS, a reduc- tion (approx. 47\%) in the incidence of any new osteoporotic fractures (vertebral and nonvertebral) was observed between the 1 st ( 0 to 6 months) and 3rd (12 to 18 months) 6-month periods of TPTD treatment.

National subanalyses are useful because local physicians are interested to know whether results from international studies can be applied to local populations. Where there are adequate national data, they may strengthen the outcomes of a multinational study. In the Greek subgroup, the incidence of fractures per 10,000 patient years was $402(n=6,2.0 \%)$ in the 1st 6-month period versus 346 fractures per 10,000 patient years $(n=5,1.7 \%)$ in the $3 \mathrm{rd}$, which reflects the total cohort. Because of the small numbers in the Greek subgroup, statistical power to show reduction in fracture rates was inadequate. However, the trend for a reduction in fracture rates is in accordance with the $47 \%$ reduction after 12-18 months shown in the total population [14].

An improvement was observed in the frequency and severity of back pain and the conduct of the patients' usual activities due to back pain. Additionally, there was a significant improvement in all examined parameters related to QoL as well as a positive effect in self-reported anxiety/ depression. The relationship between the frequency of new osteoporotic fractures and QoL of patients sustaining these 
fractures has been demonstrated in several studies [18-22]. Women with a poor response to antiosteoporotic treatment and a greater number of osteoporotic fractures had in parallel a diminished HRQoL $[22,23]$. The reduction in the frequency and severity of back pain following the 18month TPTD treatment observed in the Greek cohort, may be associated with the significant improvement in the patient HRQoL and the improvement in mobility and usual activities. Similar reductions in back pain and an improvement in reported QoL versus patients receiving placebo or comparator medication have been recorded in other studies and meta-analyses [24-28].

Osteoporosis, even without fractures, has been associated with the undesirable consequences of chronic pain, impaired physical ability, reduced social activity, poor well-being and depressed mood, which overall lead to a reduced quality of life $[20,29]$. Depression has been associated with low bone mineral density $[30,31]$ and may have an adverse impact on osteoporosis, despite methodological weaknesses of studies suggesting this preclude definitive conclusions [32]. The MORE study has shown increase of prevalence of depression among patients with osteoporosis where, in fact, postmenopausal women with vertebral fractures had greater prevalence of depressive symptoms and probable depression than those without fractures, and the number of fractures was proportional to an aggravated "Geriatric Depression Scale" score [33]. In the literature, the effect of depression or its medication on osteoporosis and bone density is more often addressed. In contrast, the effect of osteoporosis or its comorbidities (like back pain) on a patient's psychosocial condition (i.e., a combination of the patient's psychological status and the limitations on a social level caused by the disease) and the improvement that osteoporosis treatment may offer needs to be further in-vestigated. It may be hypothesized that the improvements in pain and movement limitations in our patients explain the concurrent improvement in moods.

In chronic diseases like osteoporosis, patient compliance with the administration of a medication is necessary for treatment effectiveness $[34,35]$. Despite the daily routine parenteral administration of TPTD, patient compliance with treatment in the Greek cohort remained at a remarkably high level, dropping only after 17 months (when 18 cartridges had been used). Similar levels of treatment compliance in TPTD therapy were reported in other recent studies in Europe [36, 37] and Canada [38]. On the contrary, patient adherence after 1 or 2 years of treatment with an oral antiresorptive does not exceed 50\% [39-42]. Moreover, the majority of patients $(83.1 \%)$ had previously sustained an osteoporotic fracture, despite previous administration of an antiosteoporotic medication. Disappointing results with the previous medication combined with the patients' aggravated condition outweigh the potential concerns of the daily administration of an injectable medication.

Discontinuation of TPTD treatment was low (13.6\%) due mainly to patient $(9.0 \%)$ or physician $(2.5 \%)$ decision and less to adverse events (1.8\%). This high rate of treatment completers might be interpreted in the context of improvement in back pain and QoL, observed from the first quar-ter of TPTD treatment in this study. The high number of dropouts at the 18th month of treatment compared with the 17 th $(62.4 \%$ versus $22 \%)$ may be attributed to the fact that 18 -month treatment is equal to 19 cartridges of medication prescribed (many physicians believed that they should give 18 prescriptions and thus patients completed their TPTD treatment prematurely).

Patient selection in multicenter phase III clinical studies is subject to many exclusion criteria [10-12, 24, 43]. In normal clinical practice, however, patients initiating a treatment do not necessarily demonstrate the same characteristics as those enrolled in preregistration trials. They may display multiple comorbidities or might be receiving nonevaluated concomitant medications, which would exclude them from preregistration trials. This renders observational studies an essential tool for physicians to evaluate any treatment in a naturalistic setting.

EFOS as a noncontrolled, noninterventional, observational study has a number of limitations. Firstly, the study is not designed to evaluate the cause and efficacy of TPTD but to complement randomized controlled trials to provide data on outcomes of patients treated with TPTD in normal clinical practice.

The results are specific to postmenopausal women with severe osteoporosis and may not be applicable to other patients receiving TPTD. Second, we did not determine morphometric vertebral fractures as X-rays were only performed in symptomatic patients, so we may have underestimated the effectiveness in overall risk of vertebral fracture. Third, we did not gather data on the use of analgesics during the study.

Patient compliance and continuation of treatment was assessed by questioning the patient and not verified by collection of unused medication. The high compliance may also have been encouraged by participation in the study.

Lastly, the tolerance and safety of TPTD was not one of the study objectives. Adverse events were recorded according to the standard Adverse Event Reporting procedure and are reported elsewhere for the total study.

In conclusion, as identified in the overall European EFOS population, the results of 18-month TPTD treatment in Greek osteoporotic women in common clinical practice, with comorbidities and concomitant medications indicate a significant improvement in back pain and HR_QoL.

\section{The Hellenic EFOS Study Group}

This group includes the following members Alexiou P, Boukis M, Dimopoulos N, Dreatakis K, Farchat J, Giota A, Theodorakopoulos P, Kakavouli G, Karambatsas D, Karras D, Kaskani E, Kefallinou M, Kosmidis C, Lagoudakis A, Lasithiotakis I, Lazaridis G, Maidanoglou P, Makiev G, Maltas N, Mantzilas T, Matsouka A, Notaras I, Papakitsou E, Rambidis I, Repousis P, Saddik G, Sideridis A, Stamatiadou A, Trovas $\mathrm{G}$, and Xirogiannis $\mathrm{G}$.

\section{References}

[1] W. S. Browner, A. R. Pressman, M. C. Nevitt, and S. R. Cummings, "Mortality following fractures in older women: 
the study of osteoporotic fractures," Archives of Internal Medicine, vol. 156, no. 14, pp. 1521-1525, 1996.

[2] M. C. Nevitt, B. Ettinger, D. M. Black et al., "The association of radiographically detected vertebral fractures with back pain and function: a prospective study," Annals of Internal Medicine, vol. 128, no. 10, pp. 793-800, 1998.

[3] C. Cooper, F. Jakob, C. Chinn et al., "Fracture incidence and changes in quality of life in women with an inadequate clinical outcome from osteoporosis therapy: the Observational Study of Severe Osteoporosis (OSSO)," Osteoporosis International, vol. 19, no. 4, pp. 493-501, 2008.

[4] J. Sanfélix-Genovés, I. Hurtado, G. Sanfélix-Gimeno, B. ReigMolla, and S. Peiró, "Impact of osteoporosis and vertebral fractures on quality-of-life. A population-based study in Valencia, Spain (The FRAVO Study)," Health and Quality of Life Outcomes, vol. 9, article 20, 2011.

[5] S. R. Cummings and L. J. Melton, "Osteoporosis I: epidemiology and outcomes of osteoporotic fractures," The Lancet, vol. 359, no. 9319, pp. 1761-1767, 2002.

[6] O. Johnell and J. A. Kanis, "An estimate of the worldwide prevalence and disability associated with osteoporotic fractures," Osteoporosis International, vol. 17, no. 12, pp. 1726-1733, 2006.

[7] J. A. Kanis and O. Johnell, "Requirements for DXA for the management of osteoporosis in Europe," Osteoporosis International, vol. 16, no. 3, pp. 229-238, 2005.

[8] P. D. Delmas, "Treatment of postmenopausal osteoporosis," The Lancet, vol. 359, no. 9322, pp. 2018-2026, 2002.

[9] P. Sambrook and C. Cooper, "Osteoporosis," The Lancet, vol. 367, no. 9527, pp. 2010-2018, 2006.

[10] R. M. Neer, C. D. Arnaud, J. R. Zanchetta et al., "Effect of parathyroid hormone (1-34) on fractures and bone mineral density in postmenopausal women with osteoporosis," The New England Journal of Medicine, vol. 344, no. 19, pp. 14341441, 2001.

[11] K. G. Saag, E. Shane, S. Boonen et al., "Teriparatide or alendronate in glucocorticoid-induced osteoporosis," The New England Journal of Medicine, vol. 357, no. 20, pp. 2028-2039, 2007.

[12] R. Dowd, R. R. Recker, and R. P. Heaney, "Study subjects and ordinary patients," Osteoporosis International, vol. 11, no. 6, pp. 533-536, 2000.

[13] G. Rajzbaum, F. Jakob, D. Karras et al., "Characterization of patients in the European Forsteo Observational Study (EFOS): postmenopausal women entering teriparatide treatment in a community setting," Current Medical Research and Opinion, vol. 24, no. 2, pp. 377-384, 2008.

[14] B. L. Langdahl, G. Rajzbaum, F. Jakob et al., "Reduction in fracture rate and back pain and increased quality of life in postmenopausal women treated with teriparatide: 18-month data from the European Forsteo Observational Study (EFOS)," Calcified Tissue International, vol. 85, no. 6, pp. 484-493, 2009.

[15] D. Karras, V. Drossinos, C. Barker et al., "Baseline characteristics and quality of life evaluation in Greek women with osteoporosis enrolled in the European Teriparatide Observational Study (EFOS)," Bone, vol. 20, no. 3, article 156, 2009.

[16] A. Szende and A. Williams, Eds., Measuring Self-Reported Population Health: An International Perspective Based on EQ5D, Springmed, Budapest, Hungary, 2004.

[17] A. Williams, "EuroQol—a new facility for the measurement of health-related quality of life," Health Policy, vol. 16, no. 3, pp. 199-208, 1990.

[18] S. T. Harris, N. B. Watts, H. K. Genant et al., "Effects of risedronate treatment on vertebral and nonvertebral fractures in women with postmenopausal osteoporosis: a randomized controlled trial," JAMA, vol. 282, no. 14, pp. 1344-1352, 1999.

[19] R. Lindsay, S. L. Silverman, C. Cooper et al., "Risk of new vertebral fracture in the year following a fracture," JAMA, vol. 285, no. 3, pp. 320-323, 2001.

[20] F. Salaffi, M. A. Cimmino, N. Malavolta et al., "The burden of prevalent fractures on health-related quality of life in postmenopausal women with osteoporosis: the IMOF study," Journal of Rheumatology, vol. 34, no. 7, pp. 1551-1560, 2007.

[21] A. K. Oglesby, M. E. Minshall, W. Shen, S. Xie, and S. L. Silverman, "The impact of incident vertebral and non-vertebral fragility fractures on health-related quality of life in established postmenopausal osteoporosis: results from the teriparatide randomized, placebo-controlled trial in postmenopausal women," Journal of Rheumatology, vol. 30, no. 7, pp. 1579-1583, 2003.

[22] N. M. Van Schoor, J. H. Smit, J. W. R. Twisk, and P. Lips, "Impact of vertebral deformities, osteoarthritis, and other chronic diseases on quality of life: a population-based study," Osteoporosis International, vol. 16, no. 7, pp. 749-756, 2005.

[23] C. M. Klotzbuecher, P. D. Ross, P. B. Landsman, T. A. Abbott, and M. Berger, "Patients with prior fractures have an increased risk of future fractures: a summary of the literature and statistical synthesis," Journal of Bone and Mineral Research, vol. 15, no. 4, pp. 721-739, 2000.

[24] G. Lyritis, F. Marin, C. Barker et al., "Back pain during different sequential treatment regimens of teriparatide: results from EUROFORS," Current Medical Research and Opinion, vol. 26, no. 8, pp. 1799-1807, 2010.

[25] O. Ljunggren, A. Fahrleitner-Pammer, A. Kutahov et al., "Back pain is reduced in postmenopausal women with severe osteoporosis treated with teriparatide regardless of incident fractures," Journal of Bone and Mineral Research, article S347, 2008.

[26] B. Langdahl, O. Ljunggren, W. Lems et al., "Women with severe osteoporosis treated with teriparatide improve quality of life regardless of incident fractures: a 18-month results from European Forsteo Observational Study (EFOS)," Journal of Bone and Mineral Research, article S347, 2008.

[27] M. C. Nevitt, P. Chen, R. K. Dore et al., "Reduction risk of back pain following teriparatide treatment: a meta-analysis," Osteoporosis International, vol. 16, pp. 749-756, 2005.

[28] M. C. Nevitt, P. Chen, D. P. Kiel et al., "Reduction in the risk of developing back pain persists at least 30 months after discontinuation of teriparatide treatment: a meta-analysis," Osteoporosis International, vol. 17, no. 11, pp. 1630-1637, 2006.

[29] S. Adami, D. Maugeri, V. Toscano et al., "Baseline characteristics of the population enrolled in the Italian Observational Study on Severe Osteoporosis (ISSO)," Clinical and Experimental Rheumatology, vol. 29, no. 3, pp. 477-484, 2011.

[30] G. Cizza, S. Primma, M. Coyle, L. Gourgiotis, and G. Csako, "Depression and osteoporosis: a research synthesis with metaanalysis," Hormone and Metabolic Research, vol. 42, no. 7, pp. 467-482, 2010.

[31] Q. Wu, J. H. Magnus, J. Liu, A. F. Bencaz, and J. G. Hentz, "Depression and low bone mineral density: a meta-analysis of epidemiologic studies," Osteoporosis International, vol. 20, no. 8, pp. 1309-1320, 2009.

[32] C. David, C. B. Confavreux, N. Mehsen, J. Paccou, A. Leboime, and E. Legrand, "Severity of osteoporosis: what is the impact of co-morbidities?" Joint Bone Spine, vol. 77, no. 2, pp. S103S106, 2010. 
[33] S. L. Silverman, W. Shen, M. E. Minshall, S. Xie, and K. H. Moses, "Prevalence of depressive symptoms in postmenopausal women with low bone mineral density and/or prevalent vertebral fracture: results from the Multiple Outcomes of Ral oxifene Evaluation (MORE) study," Journal of Rheumatology, vol. 34, no. 1, pp. 140-144, 2007.

[34] D. Weycker, D. Macarios, J. Edelsberg, and G. Oster, "Compliance with osteoporosis drug therapy and risk of fracture," Osteoporosis International, vol. 18, no. 3, pp. 271-277, 2007.

[35] P. Kothawala, E. Badamgarav, S. Ryu, R. M. Miller, and R. J. Halbert, "Systematic review and meta-analysis of real-world adherence to drug therapy for osteoporosis," Mayo Clinic Proceedings, vol. 82, no. 12, pp. 1493-1501, 2007.

[36] N. K. Arden, S. Earl, D. J. Fisher, C. Cooper, S. Carruthers, and M. Goater, "Persistence with teriparatide in patients with osteoporosis: the UK experience," Osteoporosis International, vol. 17, no. 11, pp. 1626-1629, 2006.

[37] K. Briot, P. Ravaud, P. Dargent-Molina, M. Zylberman, S. Liu-Leage, and C. Roux, "Persistence with teriparatide in postmenopausal osteoporosis; Impact of a patient education and follow-up program: the French experience," Osteoporosis International, vol. 20, no. 4, pp. 625-630, 2009.

[38] J. D. Adachi, D. A. Hanley, J. K. Lorraine, and M. Yu, "Assessing compliance, acceptance, and tolerability of teriparatide in patients with osteoporosis who fractured while on antiresorptive treatment or were intolerant to previous antiresorptive treatment: an 18-month, multicenter, open-label, prospective study," Clinical Therapeutics, vol. 29, no. 9, pp. 2055-2067, 2007.

[39] J. S. McCombs, P. Thiebaud, C. McLaughlin-Miley, and J. Shi, "Compliance with drug therapies for the treatment and prevention of osteoporosis," Maturitas, vol. 48, no. 3, pp. 271287, 2004.

[40] E. S. Siris, S. T. Harris, C. J. Rosen et al., "Adherence to bisphosphonate therapy and fracture rates in osteoporotic women: relationship to vertebral and nonvertebral fractures from 2 US claims databases," Mayo Clinic Proceedings, vol. 81, no. 8, pp. 1013-1022, 2006.

[41] D. Weycker, D. Macarios, J. Edelsberg, and G. Oster, "Compliance with drug therapy for postmenopausal osteoporosis," Osteoporosis International, vol. 17, no. 11, pp. 1645-1652, 2006.

[42] J. A. Cramer, M. M. Amonkar, A. Hebborn, and R. Altman, "Compliance and persistence with bisphosphonate dosing regimens among women with postmenopausal osteoporosis," Current Medical Research and Opinion, vol. 21, no. 9, pp. 14531460, 2005.

[43] J. S. Finkelstein, J. J. Wyland, H. Lee, and R. M. Neer, "Effects of teriparatide, alendronate, or both in women with postmenopausal osteoporosis," Journal of Clinical Endocrinology and Metabolism, vol. 95, no. 4, pp. 1838-1845, 2010. 


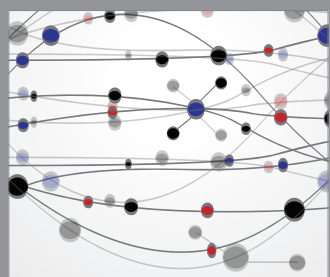

The Scientific World Journal
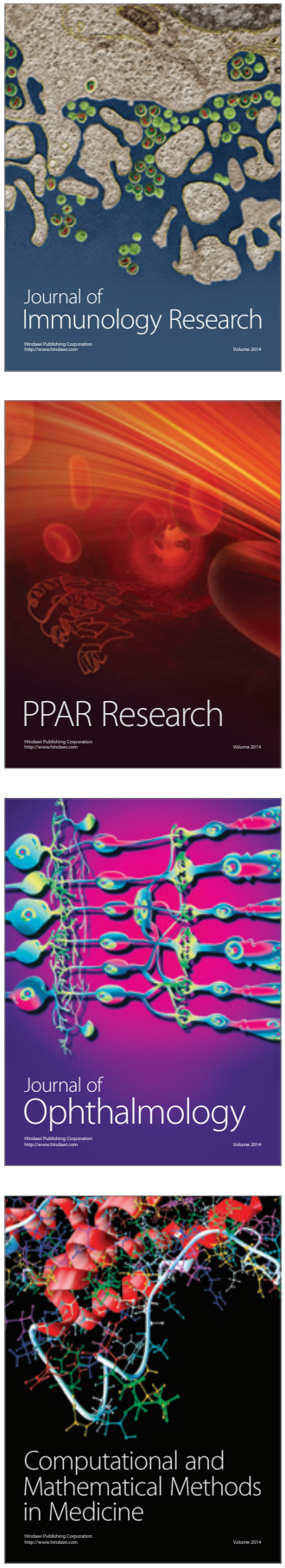

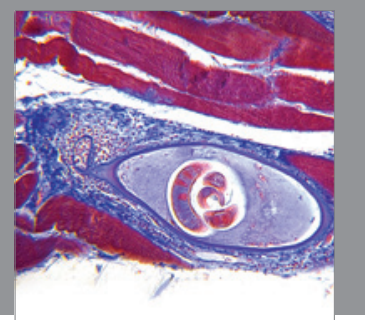

Gastroenterology

Research and Practice
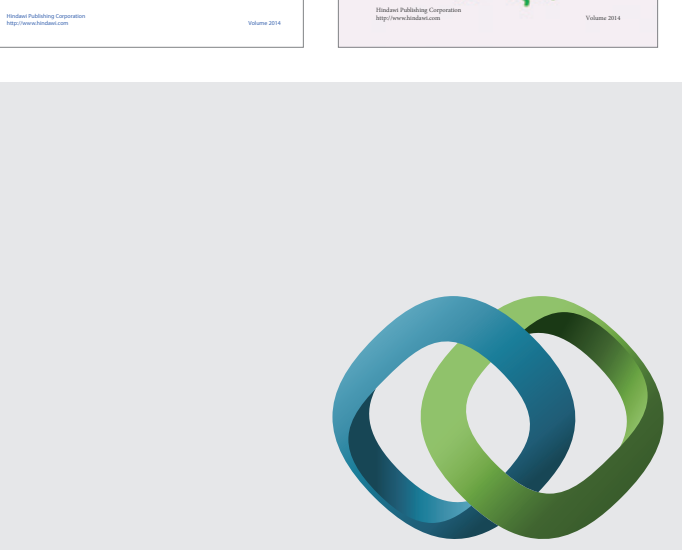

\section{Hindawi}

Submit your manuscripts at

http://www.hindawi.com
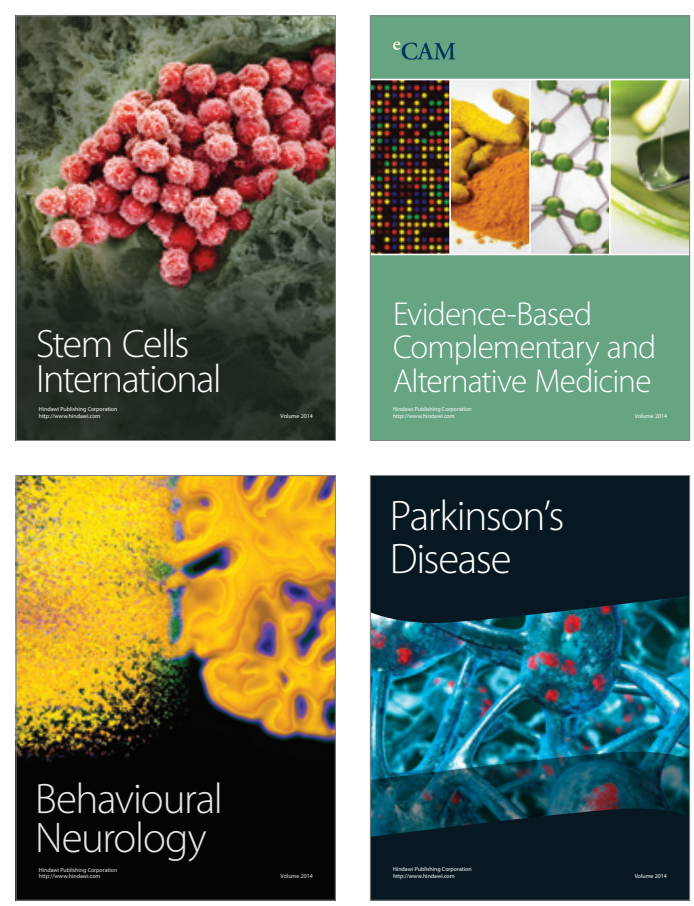

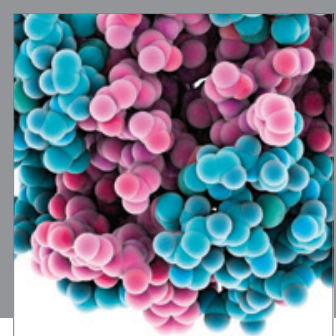

Journal of
Diabetes Research

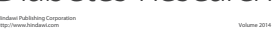

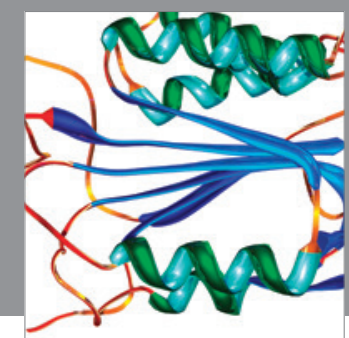

Disease Markers
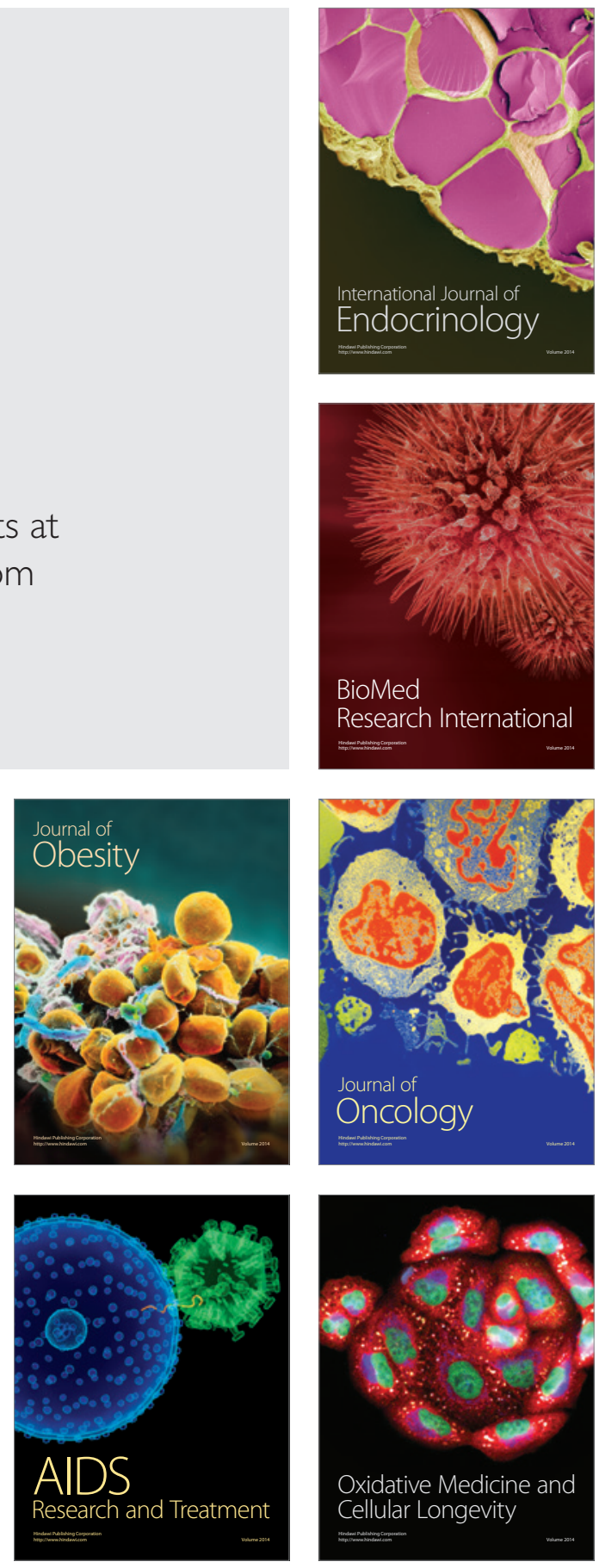